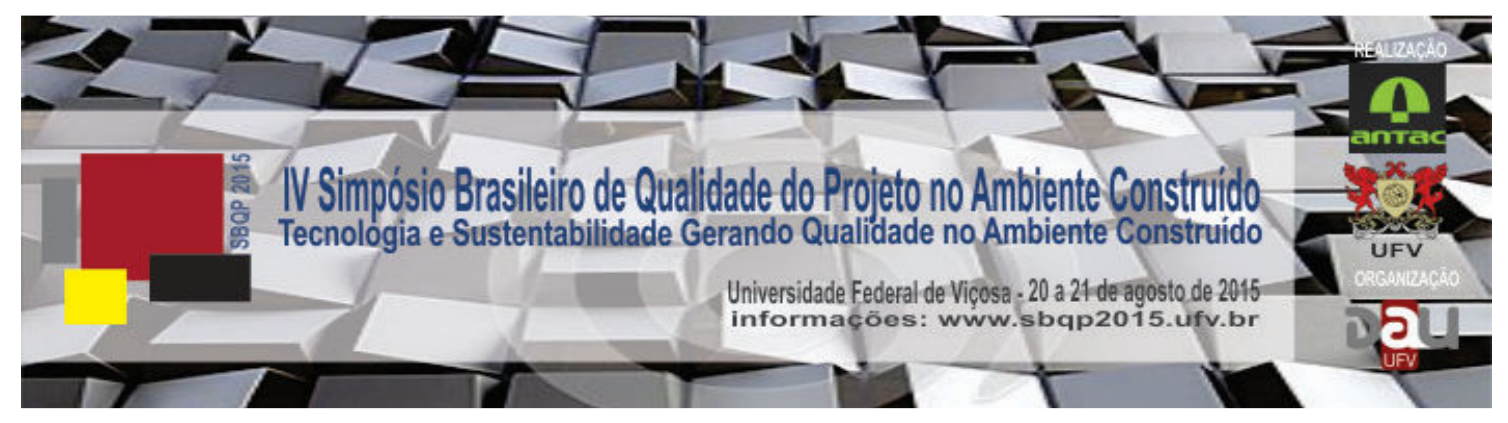

\title{
VERTICALIZAÇÃO NA CIDADE DE MACEIÓ: ESTUDO DE TIPOLOGIAS DE EDIFÍCIOS MULTIFAMILIARES (1986 A 1992)'
}

\author{
TOLEDO, Alexandre \\ Universidade Federal de Alagoas, alexandre.toledo@fau.ufal.br \\ BARBOSA, Mariana \\ Universidade Federal de Alagoas, arq.marianasb@gmail.com \\ SILVA, Bruno \\ Universidade Federal de Alagoas, arqbruno.bj@gmail.com
}

\begin{abstract}
RESUMO
O processo de verticalização na cidade de Maceió/AL aconteceu tardiamente em relação às outras capitais brasileiras. Apenas na década de 1950, surgem os primeiros edifícios altos de uso comercial e serviços com elevador. Os dois primeiros edifícios multifamiliares altos só aparecem na década de 1960. Na década seguinte até a metade da década de 1980, coincide com a promulgação do Código de Edificações de 1979, que disciplina os edifícios em altura, e do Plano Diretor de 1885, quando se presencia o crescimento e consolidação dessa tipologia arquitetônica, decorrente do crescimento da cidade, do aumento da população e do desenvolvimento do setor imobiliário e da construção civil. Entre 1986 e 1992, os Códigos de Edificações e Urbanismo receberam três Complementos, os quais alteraram alguns dispositivos desses instrumentos. Quais variações tipológicas os edifícios multifamiliares e os apartamentos apresentaram, nesse período, em decorrência dos Complementos e das novas demandas imobiliárias? O objetivo neste artigo é identificar diferentes tipologias de edifícios multifamiliares, aprovados no período de 1986 a 1992, na cidade, verificando a variação de áreas dos setores funcionais e dos ambientes. A metodologia envolveu levantamento de dados documentais no órgão municipal, coleta de dados de campo, registro fotográfico, digitalização de plantas, classificação tipológica dos edifícios e apartamentos e comparação das áreas dos setores funcionais e ambientes. Identificaram-se 112 edifícios, distribuídos em 8 bairros da cidade. Verificou-se maior diversificação de tipologias em relação aos períodos anteriores, com predominância ainda da tipologia de 3 dormitórios com dependência de empregada, seguida pela tipologia de 2 dormitórios com terceiro reversível. Constatou-se grande variação de áreas dos setores funcionais e dos ambientes por tipologia. Conclui-se que a variação de tipologias verificadas no período, expressa nos programas de necessidades e dimensionamento dos setores funcionais e dos ambientes, decorreu dos novos hábitos de morar e do perfil diversificado dos usuários.
\end{abstract}

\footnotetext{
${ }^{1}$ Trabalho apresentado no IV SBQP 2015. Universidade Federal de Viçosa. Disponível em: doi> http://dx.doi.org/10.18540/2176-4549.6033
} 
Palavras-chave: Edifícios Altos, Maceió, Processo de Verticalização, Tipologia Arquitetônica.

\begin{abstract}
The verticalization process in Maceió/AL city happened later than other Brazilian capitals. Only in the 1950's, the first hight building for commercial and service uses with elevator appeared. The first two hight multifamily buildings appeared only in the 1960's. In the next decade until the mid-1980's, coincides with the enactment of the 1979 Building Code, which governs the buildings in height, and the Master Plan of 1885, when if witnesses the growth and consolidation of this architectural typology, due to the city's growth, the increase in population and the development of real estate and construction. Between 1986 and 1992, the Buildings and Urban codes received three compliments, which altered some provisions of these instruments. What typological variations multi-family buildings and apartments presented in this period, due to the add-ons and new real estate demands? The objective of this paper is to identify different types of multi-family buildings, approved between 1986 and 1992, in the city, checking the variation of the functional areas sectors and environments. The methodology involved lifting documentary data on municipal agency, collection of field data, photographic record, plan digitization, typological classification of buildings and apartments and comparison of the areas of functional sectors and environments. We identified 112 buildings over 8 neighborhoods. A greater diversification of types compared to previous periods, predominantly still the typology of 3 bedrooms with maid bedroom, follow then the typology of 2 bedrooms with third reversible. We found wide variation in the areas of functional sectors and rooms by type. It follows that the variation in the period typologies expressed needs of the programs and design of the functional areas and rooms, held living habits of the new and diverse user profile.
\end{abstract}

Keywords: Height Buildings, Maceió, Verticalization Process, Architectural Typology.

\title{
1 INTRODUÇÃO
}

O processo de verticalização da cidade de Maceió teve início na década de 1950, com a construção dos primeiros edifícios em altura, com elevador, de uso comercial e de serviços, no Centro da cidade (SILVA, 1991). Apenas na década de 1960, surgem os primeiros edifícios residenciais multifamiliares na cidade, com a construção do edifício São Carlos, na orla do Centro e do edifício Lagoa-Mar, no bairro Farol (ALVES; TOLEDO, 2012), motivados pela instalação das primeiras construtoras na cidade e do desejo da classe média e alta em adotar hábitos de morar de outras cidades brasileiras; haja vista que não havia escassez de terrenos na cidade.

Na década seguinte (1970), o processo de verticalização residencial se intensifica, consolidando-se na década de 1980. Somente em 1979, o novo Código de Edificações do Município de Maceió ${ }^{2}$ trataria dos edifícios verticais multifamiliares. Em 1985, o Plano Diretor do Município de Maceió estabeleceu - Código de Urbanismo e o Código de Edificações ${ }^{3}$, atualizados pelos Complementos I (1989)4, II (1991)5 e III (1992)6, os quais alteraram dispositivos dos dois instrumentos.

\footnotetext{
2 Lei No 2.624, de 09 de outubro de 1979, prefeito Fernando Collor de Mello.

${ }^{3}$ Lei No 3.536 (Código de Urbanismo) e Lei No 3.537 (Código de Edificações), de 23 de dezembro de 1985, prefeito José Bandeira de Medeiros.

4 Lei No 3.943, de 09 de novembro de 1989, prefeito Guilherme Gracindo Soares Palmeira.

${ }^{5}$ Lei No 4.057, de 22 de agosto de 1991, prefeito João Sampaio.

${ }^{6}$ Lei No 4.138, de 28 de agosto de 1992, prefeito Pedro Vieira.
} 
A avaliação funcional de unidades habitacionais, sejam unifamiliares ou multifamiliares, envolve a discussão dos programas de necessidades, frente às mudanças da família nuclear brasileira, o fenômeno da miniaturização dos espaços, decorrente das restrições econômicas e ação do mercado imobiliário, e o processo de verticalização e adensamento das cidades brasileiras (BRANDÃO, 2002; TRAMONTANO, 1998).

O projeto de pesquisa teve início com o levantamento e análise dos edifícios multifamiliares aprovados no período de 1960 a 1979 (ALVES, 2012; TOLEDO; CARDOSO, 2012), que corresponde à vigência do Código de Edificações de 1957, culminando com o Código de Edificações do Município de Maceió de 1979. Nesse período, predominaram apartamentos da tipologia de 3 dormitórios com dependência completa de empregada, distribuídos em sete bairros da cidade.

A pesquisa prosseguiu com o período compreendido entre 1980 e 1985 (MARINHO; XAVIER; TOLEDO, 2012), que corresponde à vigência do Código de Edificações de 1979 até a promulgação do Plano Diretor do Município de Maceió de 1985. Nesse período, verifica-se a diversificação tipológica com oferta de apartamentos das tipologias de 1 e 2 dormitórios e de apartamentos com dormitório reversível, em substituição da dependência completa de empregada. A ocupação avança para novos bairros como Mangabeiras, Ponta Verde, Jatiúca e Cruz das Almas (XAVIER, 2012).

O período de 1986 a 1992 corresponde ao crescimento acelerado da população de Maceió, concomitante ao desenvolvimento do setor turístico, o qual promoveu a construção de hotéis verticais na orla da cidade, contribuindo decisivamente para o processo de verticalização e adensamento dos novos bairros da baixada litorânea: Ponta Verde, Jatiúca e Cruz das Almas.

Diante do exposto, as questões que se colocam são: Em quais bairros se construíram esses edifícios na cidade de Maceió, no período de 1986-1992? Quais variações tipológicas os edifícios multifamiliares e os apartamentos apresentaram, em decorrência dos Complementos dos instrumentos do Plano Diretor? Quais mudanças de programa e dimensionamento de ambientes ocorreram? Quais alterações espaciais se verificam em função das novas demandas imobiliárias?

O objetivo deste artigo é identificar diferentes tipologias de edifícios multifamiliares, aprovados no período de 1986 a 1992, na cidade de Maceió, verificando a variação de áreas dos setores funcionais e dos ambientes dos apartamentos.

\section{FUNDAMENTAÇÃO}

O estudo da habitação levará sempre a um resultado da sua natureza dinâmica, com significados que abrangem várias áreas de conhecimento. Isso ocorre porque a moradia deve atender a diferentes necessidades, diferentes famílias, diferentes estilos de vida. Tornando-se possível e necessário a consideração de uma maior diversidade de arranjos espaciais (BRANDÃO, 2002). 
Em Arquitetura, o termo tipologia é utilizado de forma frequente para designar a forma-base dos edifícios, isto é, a estrutura interna da forma, o princípio que implica em si a possibilidade de infinitas variantes formais, aquilo que diferentes projetos têm em comum, a ideia ou referencial que serve de regra ao modelo final. Atualmente se faz uso tanto superficial quanto específico para o termo tipologia.

Em um extremo assimila-se tipo a uma figura geométrica ou referência geral, tornando o sentido extremamente vago. Em outro, chega-se a falar de diferentes tipologias de apartamentos para aludir a uma pequena variedade de plantas, as quais só diferem entre si no número de dormitórios, sem alteração nas normas de distribuição (MARTíNEZ, 2000).

Brandão (2002), na classificação tipológica dos apartamentos, considera a forma geral, a circulação interna, a distribuição dos ambientes e a interconexão dos setores. A classificação final leva em conta o conteúdo programático, expresso, sobretudo pela quantidade de dormitórios e banheiros. O autor estratificou mais de 80 diferentes tipologias de apartamentos brasileiros.

Tramontano (1997) mostra que a nuclearização da tipologia de apartamentos, tão presente nos edifícios multifamiliares, foi concebida ainda no período moderno, no qual o perfil doméstico era tradicionalmente composto pelo pai, mãe e filho (família nuclear), e que esse perfil vem sendo substituído ao longo das décadas. Ao contrário do que deveria ocorrer, mesmo observando as distintas necessidades de abrigar novas atividades e usos no espaço doméstico, a tipologia dos apartamentos pouco se tem alterado, reproduzindo o mesmo modelo de habitação tripartido em zonas social, íntima e de serviço. Tramontano (2000) agrupou os apartamentos em apenas 6 categorias.

Schneider (1998) classificou as plantas dos apartamentos em 8 categorias distintas. A categoria separação das áreas funcionais corresponde ao modelo de habitação tripartido apontado por Tramontano (1997).

Porém, quando se trata de edifícios multifamiliares, o que se verifica na tipologia habitacional destes apartamentos é uma racionalidade na sua forma de organização, a tripartição em setores social/íntimo/serviço. A partir dessa estrutura inicial pouco se modifica, percebendo-se pequena variedade nas suas plantas, não constituindo, pois, uma variedade tipológica (TRAMONTANO, 1995).

\section{MÉTODO}

O trabalho envolveu pesquisa documental, mediante levantamento e análise de dados fornecidos pela Secretaria de Controle e Convívio Urbano (SMCCU) do município de Maceió, identificação de tipologias dos apartamentos e comparação de áreas dos ambientes e dos setores funcionais dos apartamentos.

A metodologia compreendeu as seguintes etapas: complementação de informações cadastrais do banco de dados do Grupo de Estudos em Projeto 
de Arquitetura (gEPA), referente ao período 1986-1992; elaboração de fichas individuais de cada edifício e de gráficos comparativos das tipologias de apartamentos por ano; cálculo das áreas dos ambientes e setores funcionais dos apartamentos, com auxílio da ferramenta AutoCAD.

Para a complementação das informações cadastrais, realizou-se levantamento de dados nos arquivos da SMCCU, nos quais os edifícios são registrados de acordo com o ano de entrada do pedido de aprovação do projeto. Como neste período (1986-1992) ainda não havia informações digitalizadas, fotografaram-se as pranchas e posteriormente digitalizaram-se as plantas baixas do pavimento tipo e cobertura (quando existente), com auxílio do programa AutoCAD. Após a digitalização, calcularam-se as áreas de todos os ambientes e dos setores funcionais de cada apartamento.

Essas informações serviram para elaboração das fichas dos edifícios contendo as seguintes informações: número de registro do edifício na SMCCU, ano do registro, bairro, autor do projeto, número de pavimentos, número de apartamento por andar, número de dormitórios (tipologia), localização por endereço e por mapa retirado do Google Street View, construtora que executou o projeto, existência ou não de dependência de empregada e varanda, imagem da fachada também retirada do Google Street View, planta baixa do pavimento tipo e cobertura (quando existente), quadro de área útil dos apartamentos com informações por ambiente e por setor, além da planta baixa de cada unidade de apartamento.

O enquadramento tipológico levou em conta o conteúdo programático, expresso sobretudo pela quantidade de dormitórios e banheiros, segundo Brandão (2002). A análise comparativa do dimensionamento dos ambientes considerou as áreas úteis dos mesmos (medidas internas, sem considerar as paredes). A área dos setores funcionais dos apartamentos considerou a soma das áreas dos ambientes que os integram.

Consideraram-se os três setores funcionais apontados por Tramontano (1998): social, íntimo e serviço, envolvendo os seguintes ambientes:

- Setor social - salas de estar e jantar, lavabos, varandas de uso comum e gabinetes, se acessados pela área social.

- Setor íntimo - estar íntimo, dormitórios, banheiros, suítes, closet e varandas privativas.

- Setor de serviço - cozinha, área de serviço, despensa e dependência de empregada (dormitório e banheiro).

\section{RESULTADOS E DISCUSSÃO}

Identificaram-se 112 edifícios registrados na SMCCU, no período estudado (Quadro 1). O ano de 1987 apresentou o maior número de projetos aprovados, com 33 edifícios (29\%); enquanto que, nos demais anos, esse número variou entre 8 (7\%), em 1986, e 17 (15\%) edifícios, em 1988 e 1990 (Gráfico 1).

Quadro 1 - Distribuição dos edifícios multifamiliares do período de 1986 $-1992$

\begin{tabular}{|c|c|c|c|c|c|}
\hline Ano & Qt. & Bairro & \multicolumn{3}{|c|}{ Tipologia } \\
\hline 198 & 8 & $\begin{array}{l}\text { Farol(2)/ Jatiúca(2)/ } \\
\text { Ponta Verde(4) }\end{array}$ & \begin{tabular}{|l|} 
2DO+DE(1) \\
2DO+RE(2)
\end{tabular} & $3 D O+D E(6)$ & $4 \mathrm{DO}+\mathrm{DE}(1)$ \\
\hline
\end{tabular}




\begin{tabular}{|c|c|c|c|c|c|c|c|}
\hline 6 & & & & & & & \\
\hline $\begin{array}{c}198 \\
7\end{array}$ & 33 & $\begin{array}{c}\text { Farol(2)/Jatiúca(1 1)/ } \\
\text { Pajuçara(1)/ Poço(1)/ } \\
\text { Ponta Verde(17)/ } \\
\text { Prado(1) }\end{array}$ & $\begin{array}{c}1 \mathrm{DO}(2) \\
1 \mathrm{DO}+\mathrm{DE} \\
(1)\end{array}$ & $\begin{array}{l}\text { 2DO+DE(4) } \\
\text { 2DO+RE(7) }\end{array}$ & $\begin{array}{c}3 \mathrm{DO}(4) \\
3 \mathrm{DO}+\mathrm{DE}(12 \\
1\end{array}$ & $\begin{array}{l}4 D O+D E(5) \\
4 D O+2 D E(2)\end{array}$ & $\begin{array}{c}5 \mathrm{DO}+2 \\
\mathrm{DE}(1)\end{array}$ \\
\hline $\begin{array}{c}198 \\
8\end{array}$ & 17 & $\begin{array}{c}\text { Jatiúca(5)/ } \\
\text { Mangabeiras (1)/ } \\
\text { Poço(1)/ Ponta da } \\
\text { Terra(1)/ Ponta } \\
\text { Verde(9) }\end{array}$ & 1DO(1) & $\begin{array}{l}\text { 2DO+DE(1) } \\
2 \mathrm{DO}+\mathrm{RE}(5)\end{array}$ & $\begin{array}{c}3 \mathrm{DOO}(1) \\
3 \mathrm{DO}+\mathrm{DE}(6) \\
3 \mathrm{DO}+\mathrm{RE}(1)\end{array}$ & $\begin{array}{l}4 \mathrm{DO}+\mathrm{DE}(1) \\
4 \mathrm{DO}+2 \mathrm{DE}(2)\end{array}$ & \\
\hline $\begin{array}{c}198 \\
9\end{array}$ & 12 & $\begin{array}{c}\text { Jatiúca(3)/ Ponta } \\
\text { Verde(9) }\end{array}$ & & $\begin{array}{l}\text { 2DO+DE(1) } \\
2 \mathrm{DO}+\mathrm{RE}(4)\end{array}$ & $\begin{array}{l}3 \mathrm{DO}+\mathrm{DE}(4) \\
3 \mathrm{DO}+\mathrm{RE}(1)\end{array}$ & $4 \mathrm{DO}+\mathrm{DE}(3)$ & \\
\hline $\begin{array}{c}199 \\
0\end{array}$ & 17 & $\begin{array}{l}\text { Farol(1)/ Jatiúca(5)/ } \\
\text { Mangabeiras(1)/ } \\
\text { Pajuçara(3)/ Ponta } \\
\text { Verde(7) }\end{array}$ & & $\begin{array}{c}2 \mathrm{DO}(2) \\
2 \mathrm{DO}+\mathrm{RE}(6)\end{array}$ & $\begin{array}{c}3 \mathrm{DO}(2) \\
3 \mathrm{DO}+\mathrm{DE}(4)\end{array}$ & $4 \mathrm{DO}+\mathrm{DE}(3)$ & \\
\hline $\begin{array}{c}199 \\
1\end{array}$ & 12 & $\begin{array}{c}\text { Farol(1)/ Jatiúca(4)/ } \\
\text { Ponta Verde(6) }\end{array}$ & $1 D O(2)$ & $\begin{array}{c}2 \mathrm{DO}(1) \\
2 \mathrm{DO}+\mathrm{RE}(2) \\
\end{array}$ & $\begin{array}{c}3 \mathrm{DO}(2) \\
3 \mathrm{DO}+\mathrm{DE}(4)\end{array}$ & $\begin{array}{l}4 D O+D E(1) \\
4 D O+2 D E(1)\end{array}$ & \\
\hline $\begin{array}{c}199 \\
2\end{array}$ & 13 & $\begin{array}{c}\text { Jatiúca(7)/ } \\
\text { Pajuçara(1)/ Poço(1)/ } \\
\text { Ponta Verde(4) }\end{array}$ & $1 \mathrm{DO}(1)$ & $\begin{array}{c}2 \mathrm{DO}(2) \\
2 \mathrm{DO}+\mathrm{DE}(1) \\
2 \mathrm{DO}+\mathrm{RE}(6)\end{array}$ & $3 D O+D E(2)$ & $4 \mathrm{DO}+\mathrm{DE}(2)$ & \\
\hline $\begin{array}{c}\text { Tota } \\
\text { I }\end{array}$ & 112 & $\begin{array}{c}\text { Farol(6)/ Jatiúca(37)/ } \\
\text { Mangabeiras(2)/ } \\
\text { Pajuçara(5)/ Poço(3)/ } \\
\text { Ponta Verde(56)/ Ponta } \\
\text { da Terra(1) / Prado(1) }\end{array}$ & $\begin{array}{c}1 \mathrm{DO}(6) \\
1 \mathrm{DO}+\mathrm{DE} \\
(1)\end{array}$ & $\begin{array}{c}2 \mathrm{DO}(5) \\
2 \mathrm{DO}+\mathrm{DE}(10 \\
1 \\
2 \mathrm{DO}+\mathrm{RE}(32 \\
)\end{array}$ & $\begin{array}{c}3 \mathrm{DO}(9) \\
3 \mathrm{DO}+\mathrm{DE}(38 \\
1 \\
3 \mathrm{DO}+\mathrm{RE}(2)\end{array}$ & $\begin{array}{l}4 D O+D E(16) \\
4 D O+2 D E(5)\end{array}$ & $\begin{array}{l}5 \mathrm{DO}+2 \\
\mathrm{DE}(1)\end{array}$ \\
\hline
\end{tabular}

Legenda: DO - dormitórios, DE - dependência de empregada, RE - reversível

\section{Gráfico 1 - Distribuição dos edifícios multifamiliares do período 1986 - 1992}

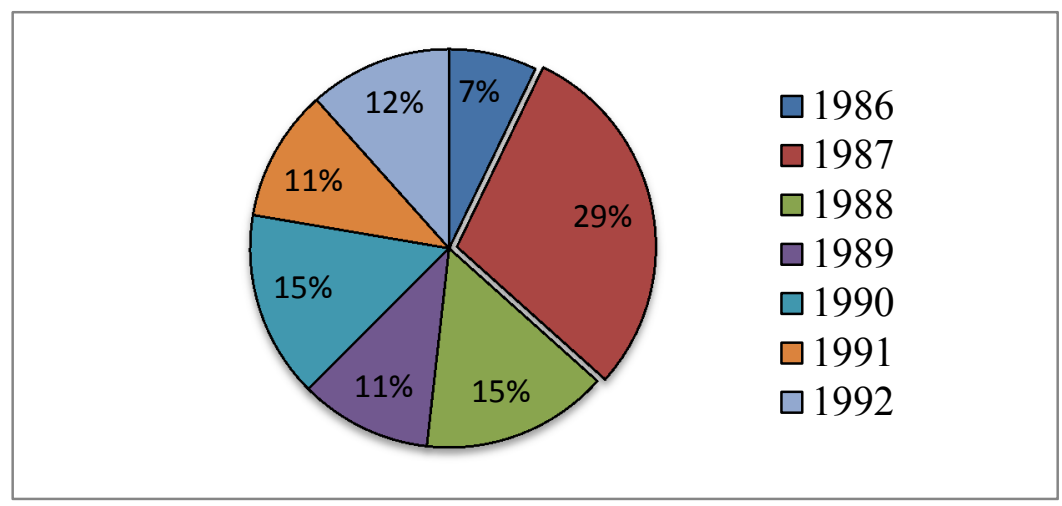

\section{Distribuição dos edifícios nos bairros}

Verificou-se a distribuição dos edifícios em 8 bairros da cidade: Farol, Jatiúca, Mangabeiras, Pajuçara, Poço, Ponta da Terra, Ponta Verde e Prado. O bairro Ponta Verde apresentou a maior quantidade de edifícios verticais com 57 ocorrências (51\%), seguido do bairro Jatiúca, com 37 edifícios (33\%); já os bairros Ponta da Terra e Prado, apresentaram apenas um edifício cada (Gráfico 2).

Considerando que a cidade de Maceió possuía 25 bairros no período, esse resultado demonstra a grande concentração do processo de verticalização em dois bairros apenas (84\%), e a pequena expansão para três novos bairros: Mangabeiras, Poço e Ponta da Terra, sem ocorrências de edifícios verticais em altura até o Plano Diretor de 1985 (Figura 1). Esse processo de verticalização 
transcorreu em paralelo ao lançamento de loteamentos fechados horizontais de alto padrão, na parte alta da cidade.

\section{Gráfico 2 - Distribuição dos edifícios multifamiliares por bairros}

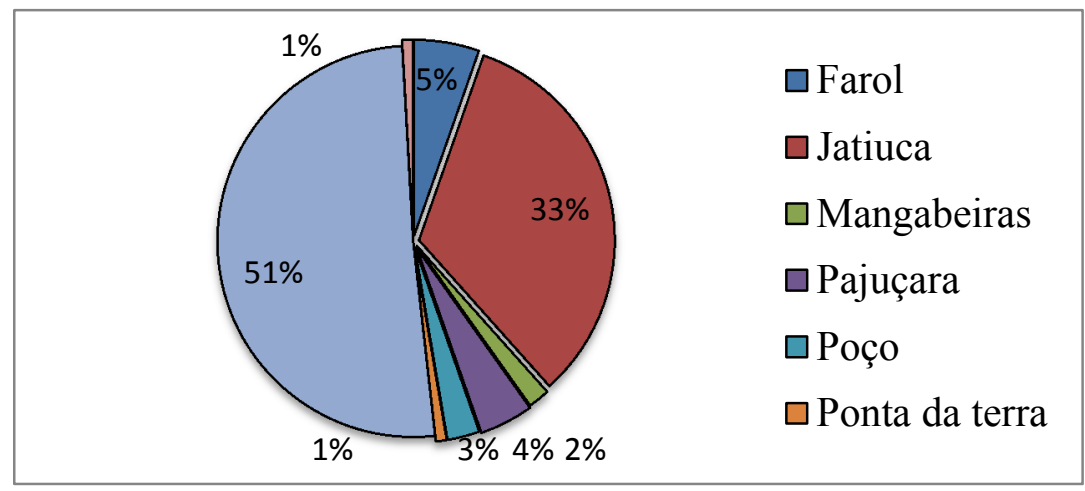

\section{Figura 1 - Vista aérea da cidade de Maceió-AL no final da década de 1980}

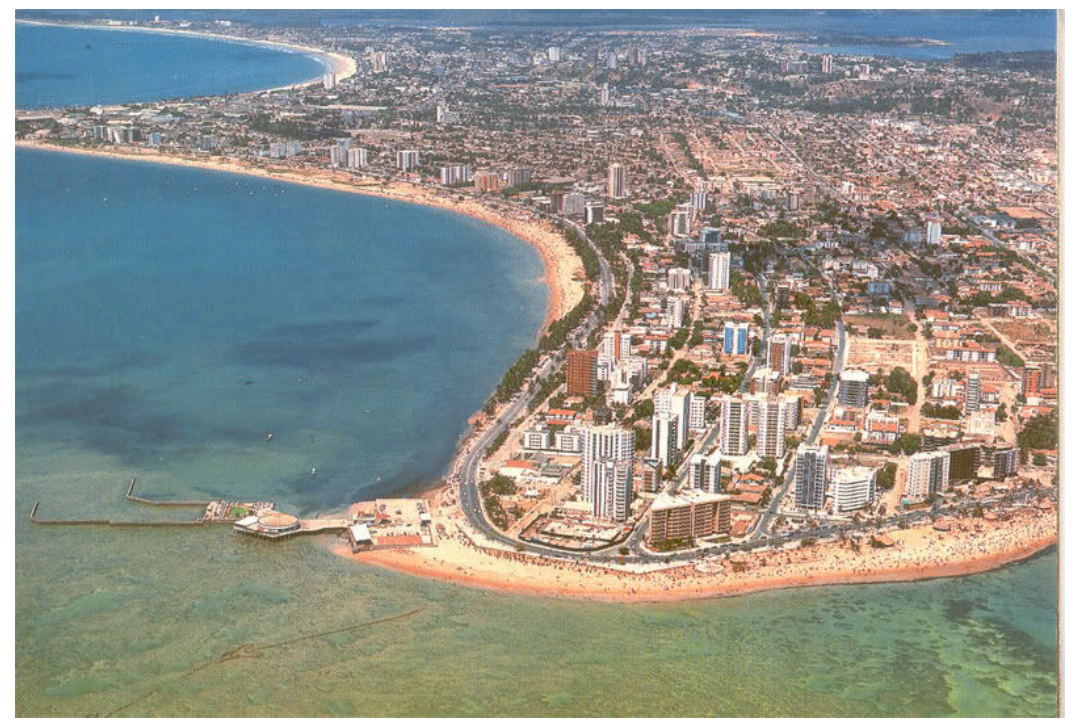

\section{Variações tipológicas dos apartamentos}

A diversidade de tipologias encontradas foi grande, com variação de 1 até 5 dormitórios, além da presença de muitos edifícios verticais híbridos - aqueles que possuem mais de uma tipologia de apartamentos no pavimento tipo. Prevaleceu a tipologia de 3 dormitórios com dependência de empregada (38 unidades), cuja tipologia, considerando-se as variações de sem dependência de empregada e com dormitório reversível, totaliza 49 unidades; seguida pela tipologia de 2 dormitórios com o terceiro reversível (32 unidades), cuja tipologia, considerando-se as variações com apenas 2 dormitórios e 2 dormitórios mais dependência de empregada, totaliza 47 unidades (Gráfico 3).

\section{Gráfico 3 - Distribuição dos edifícios multifamiliares por tipologia}




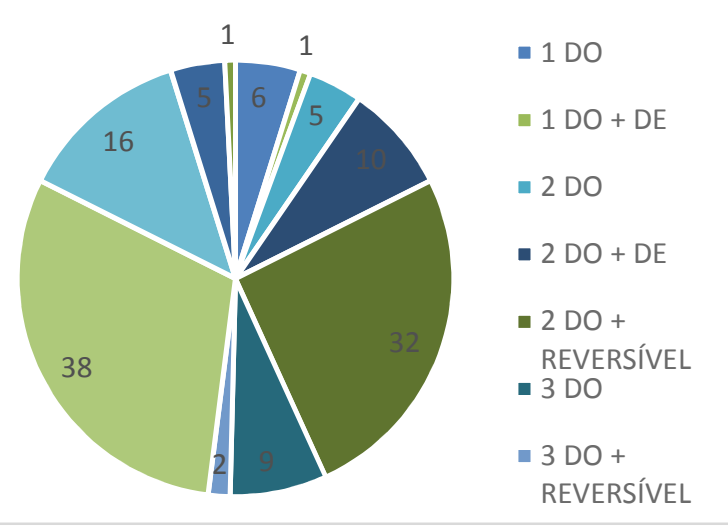

Variações das áreas dos ambientes e dos setores funcionais

As áreas dos setores funcionais dentro de uma mesma tipologia variaram bastante (Quadro 2). Além da presença de grandes coberturas, duplex ou não, a tipologia de 4 dormitórios com dependência de empregada apresentou as maiores variações.

\section{Quadro 2 - Variação das áreas por setores em cada tipologia de apartamento}

\begin{tabular}{|c|c|c|c|}
\hline Tipologia & Setor & $\begin{array}{c}\text { Menor Área } \\
\left(\mathrm{m}^{2}\right)\end{array}$ & Maior Área $\left(\mathrm{m}^{2}\right)$ \\
\hline \multirow{3}{*}{1 dormitório } & Social & 16,20 & 24,45 \\
\hline & Íntimo & 14,70 & 19,60 \\
\hline & Serviço & 4,90 & 10,70 \\
\hline \multirow{3}{*}{$\begin{array}{l}1 \text { dormitório + } \\
\text { dependência }\end{array}$} & Social & 17,35 & - \\
\hline & Íntimo & 13,85 & - \\
\hline & Serviço & 17,30 & - \\
\hline \multirow{3}{*}{2 dormitórios } & Social & 17,55 & 19,95 \\
\hline & Íntimo & 21,90 & 22,05 \\
\hline & Serviço & 12,30 & 12,35 \\
\hline \multirow{3}{*}{$\begin{array}{l}2 \text { dormitórios + } \\
\text { dependência }\end{array}$} & Social & 21,40 & 31,10 \\
\hline & Íntimo & 27,55 & 30,75 \\
\hline & Serviço & 17,55 & 35,75 \\
\hline \multirow{3}{*}{2 dormitórios + reversível } & Social & $19,50 \mathrm{~m}^{2}$ & $51,65 \mathrm{~m}^{2}$ \\
\hline & Íntimo & $24.87 \mathrm{~m}^{2}$ & $70.89 m^{2}$ \\
\hline & Serviço & $10.70 \mathrm{~m}^{2}$ & $26,65 \mathrm{~m}^{2}$ \\
\hline \multirow{3}{*}{3 dormitórios } & Social & $19,58 \mathrm{~m}^{2}$ & $31,62 \mathrm{~m}^{2}$ \\
\hline & Íntimo & $29,76 \mathrm{~m}^{2}$ & $41,85 \mathrm{~m}^{2}$ \\
\hline & Serviço & $12,88 \mathrm{~m}^{2}$ & $25,14 \mathrm{~m}^{2}$ \\
\hline \multirow{3}{*}{$\begin{array}{l}4 \text { dormitórios + } \\
\text { dependência }\end{array}$} & Social & 49,25 & 120,05 \\
\hline & Íntimo & 73,45 & 132,85 \\
\hline & Serviço & 26,60 & 56,60 \\
\hline \multirow{3}{*}{$\begin{array}{l}4 \text { dormitórios + } 2 \\
\text { dependências }\end{array}$} & Social & 61,00 & 95,75 \\
\hline & Íntimo & 93,05 & 129,15 \\
\hline & Serviço & 43,80 & 50,30 \\
\hline
\end{tabular}

O edifício Porchat, localizado no bairro Farol, na parte alta da cidade, com $150,10 \mathrm{~m}^{2}$ de área útil (Figura 2), e o edifício Tartana, situado no bairro Ponta Verde, na orla oceânica, com 391,30 $\mathrm{m}^{2}$ de área útil (Figura 3), ambos da tipologia de 4 dormitórios, demonstram que a variação de áreas dos 
ambientes e setores encontrada não permite afirmar que o processo de miniaturização se verifica nesse período, nos edifícios de alto padrão.

Figura 2 - Planta do edifício Porchat de 4 dormitórios com menor área

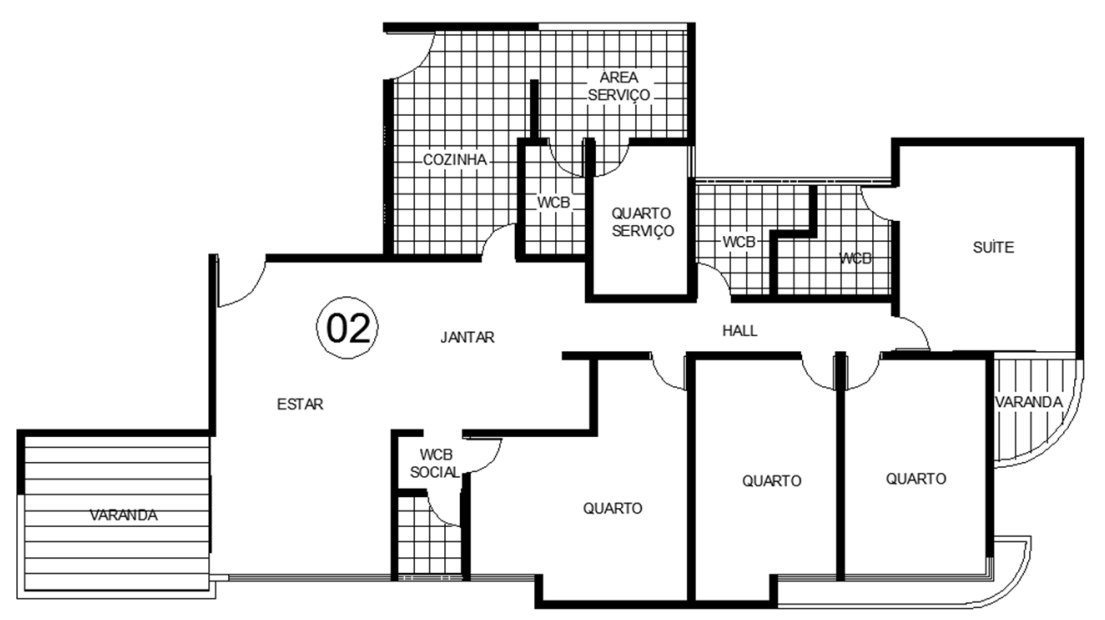

Figura 3 - Planta do edifício Tartana de 4 dormitórios com maior área

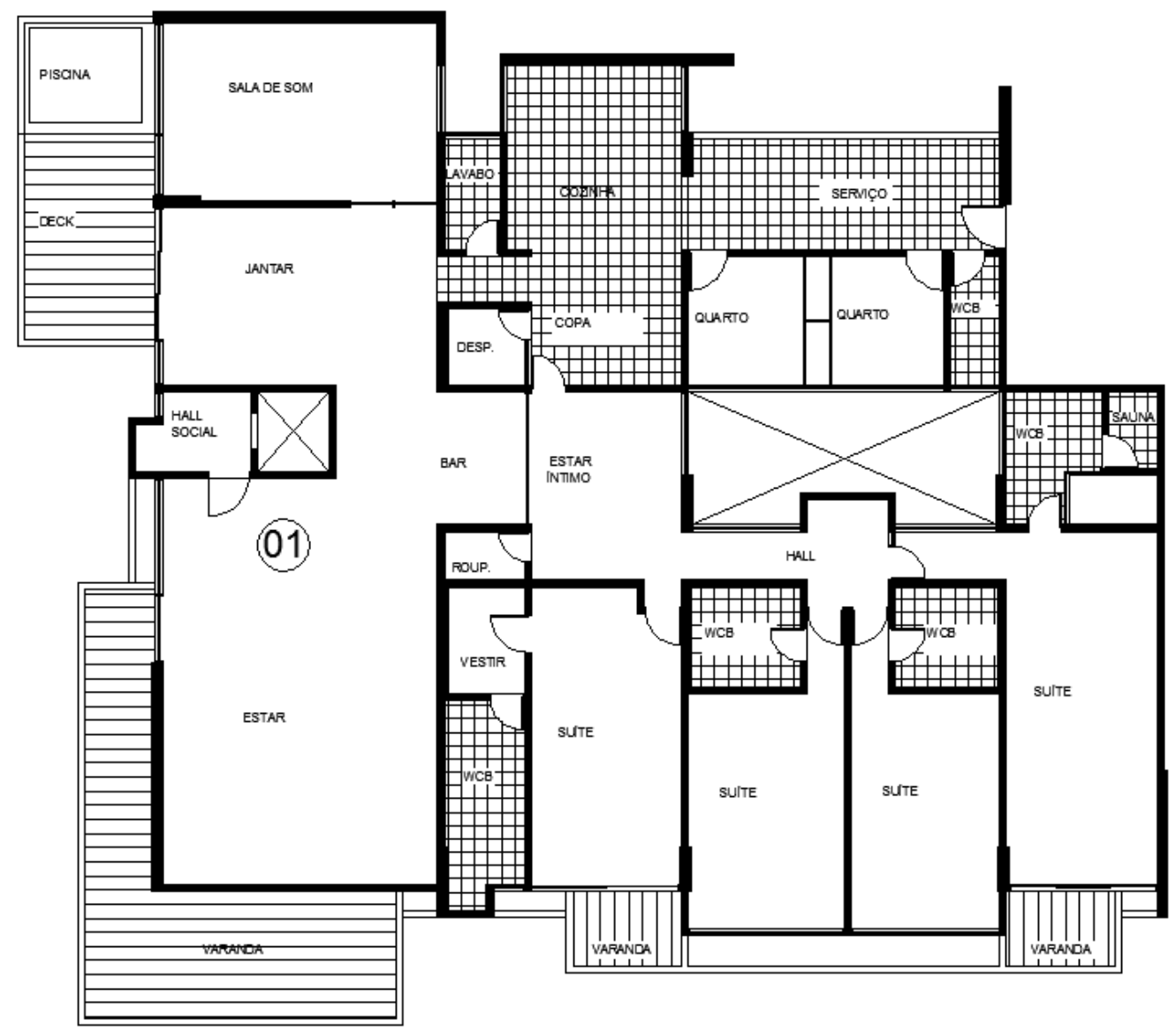

\section{CONCLUSÃO}

Neste artigo, verificou-se a diversidade tipológica e a variação de áreas dos setores funcionais e dos ambientes dos apartamentos aprovados na cidade 
de Maceió, no período de 1986-1992. Utilizou-se levantamento documental e análise e catalogação de dados.

Constatou-se a diversidade tipológica, com identificação de apartamentos de 1 dormitório até 5 dormitórios. A tipologia de 3 dormitórios com dependência de empregada prevaleceu, como nos períodos anteriores, seguida da tipologia de 2 dormitórios com terceiro reversível. Verificou-se grande variação de áreas dos ambientes e setores funcionais, por tipologia. A maior variação ocorreu na tipologia de 4 dormitórios.

A variação tipológica decorre possivelmente dos novos hábitos de morar, do perfil familiar diversificado e do padrão econômico dos novos usuários. Nas próximas etapas, se realizará o levantamento e análise dos edifícios do período de 1992 a 2005, quando o município de Maceió aprovou o atual Plano Diretor.

\section{AGRADECIMENTOS}

Ao CNPq, pelo apoio recebido do Programa Institucional de Bolsas de Iniciação Científica.

\section{REFERÊNCIAS}

ALVES, M. E. M., TOLEDO, A. M. Edifícios São Carlos e Lagoa-Mar: o início da verticalização multifamiliar na cidade de Maceió-AL (1960) In: II Encontro da Associação Nacional de Pesquisa e Pós-Graduação em Arquitetura e Urbanismo, 2012, Natal/RN. Anais do II ENANPARQ. P. 1-19. Rio de Janeiro: ANPARQ, 2012.

ALVES, M. E. M. O início da verticalização em Maceió-AL: um estudo tipológico dos edifícios multifamiliares em altura (1960-1970). 2012. Dissertação (Mestrado em Arquitetura e Urbanismo: Dinâmicas do Espaço Habitado) - Faculdade de Arquitetura e Urbanismo da Universidade Federal de Alagoas. Maceió.

BRANDÃO, D. Q. Diversidade e potencial de flexibilidade de arranjos espaciais de apartamentos. Florianópolis, 2002. Tese (Doutorado em Engenharia de Produção) - Departamento de Engenharia de Produção da Universidade Federal de Santa Catarina, Florianópolis.

MARINHO, B.Q.C., XAVIER, M.R.N.G., TOLEDO, A. M. Análise da funcionalidade de edifícios multifamiliares de diferentes tipologias aprovados no período de 1980-1985 em Maceió/AL In: XIV Encontro Nacional de Tecnologia do Ambiente Construído, 2012, Juiz de Fora/MG. ENTAC: Encontro Nacional de Tecnologia do Ambiente Construído. p.1-6. Porto Alegre: ANTAC/UFJF, 2012.

MARTÍNEZ, A. C. Ensaio sobre o projeto. Brasília: Editora Universidade de Brasília, 2000.

SILVA, M. A. Arquitetura moderna - a atitude alagoana 1950-1964. Maceió: SERGASA, 1991.

SCHNEIDER, F. Atlas de plantas: viviendas. Barcelona: Gustavo Gilli, 1998.

TOLEDO, A. M., CARDOSO, Y. S. Análise funcional de edifícios de apartamentos construídos em Maceió - AL na década de 1970 ln: Il Encontro da Associação Nacional de Pesquisa e Pós-Graduação em Arquitetura e Urbanismo, 2012, Natal/RN. Anais do II ENANPARQ. p. 1-18. Rio de Janeiro: ANPARQ, 2012. 
TRAMONTANO, M. C. Novos modos de vida, novos espaços de morar, Paris, São Paulo, Tokyo: uma reflexão sobre a habitação contemporânea. 1998. Tese. (Doutorado em Arquitetura e Urbanismo) - Faculdade de Arquitetura da Universidade de São Paulo, São Paulo.

Habitação contemporânea. São Carlos, 1995.

XAVIER, R. N. G. O Recurso da Flexibilidade no Projeto de Edifícios Multifamiliares em Maceió/AL no Período de 1980-1985. 2012. Exame de qualificação (Mestrado em Arquitetura e Urbanismo: Dinâmicas do Espaço Habitado). Faculdade de Arquitetura e Urbanismo da Universidade Federal de Alagoas, Maceió. 